\title{
LETTER
}

\section{Bivalirudin and post-cardiotomy ECMO: a word of caution}

\author{
Marco Ranucci* \\ See related research by Ranucci et al., http://ccforum.com/content/15/6/R275
}

\begin{abstract}
Bivalirudin has been proposed as the sole anticoagulant in patients under extracorporeal membrane oxygenation (ECMO) or cardiopulmonary bypass. Owing to the pharmacodynamic properties of bivalirudin, areas of blood stagnation should be carefully avoided in order to limit the risk of thrombosis. The ECMO circuit has no reservoir and is usually devoid of blood stagnation areas. Conversely, under some circumstances, intracardiac blood stagnation areas may exist. In this case, there is a potential risk for the spontaneous formation of an intracardiac thrombus. We suggest that, under bivalirudin anticoagulation, a minimal degree of intracardiac blood flow with left heart valve movement is allowed.
\end{abstract}

In a recent issue of Critical Care [1], we presented a series of 13 patients undergoing post-cardiotomy extracorporeal membrane oxygenation (ECMO) with bivalirudinbased anticoagulation. After this series, we satisfactorily continued this experience, reaching about 20 patients treated. However, we think that a word of caution should be added to our recently published experience.

Owing to its pharmacological profile, bivalirudin is rapidly cleaved by proteolytic enzymes, and its half-life is about 25 minutes when the renal function is normal [2]. The use of bivalirudin for cardiopulmonary bypass (CPB) [3] and ECMO [4] is a feasible option. However, it is recommended that, during $\mathrm{CPB}$, blood stagnation in the circuit be avoided because the rapid cleavage of bivalirudin may result in thrombosis. The ECMO circuit is devoid of a reservoir, and therefore blood stagnation is usually not a circuit-related problem. Conversely, under some circumstances, the cardiac chambers may act as a 'natural reservoir', which entails blood stagnation and the

*Correspondence: cardioanestesia@virgilio.it

Department of Cardiothoracic and Vascular Anesthesia and Intensive Care, IRCCS Policlinico San Donato, Via Morandi 30, 20097 San Donato Milanese (Milan) Italy risk for spontaneous intracardiac thrombosis. This is particularly true in the case of a very large right or left atrium with insufficient venous drainage or the case of very poor ventricular systolic function with intraventricular blood stagnation.

To avoid this condition, we think that maintaining a partial ECMO support, leaving a minimal degree of intracardiac blood flow, may be a reasonable choice. This may be checked by echocardiographic view of heart valve movement or simply by the observation of some degree of pulsatile arterial blood pressure.

We think that, in the event of echocardiographic evidence of a 'smoke effect' within one or more cardiac chambers, bivalirudin should be replaced by standard heparin anticoagulation. Intracardiac thrombus formation during ECMO with heparin anticoagulation has been described as well [5], but the pharmacokinetic properties of heparin may limit the risk of thrombus formation due to blood stagnation.

\section{Abbreviations}

$\mathrm{CPB}$, cardiopulmonary bypass; ECMO, extracorporeal membrane oxygenation.

\section{Competing interests}

The author declares that he has no competing interests.

Published: 9 May 2012

\section{References}

1. Ranucci M, Ballotta A, Kandil H, Isgrò G, Carlucci C, Baryshnikova E, Pistuddi V: Bivalirudin-based versus conventional heparin anticoagulation for postcardiotomy extracorporeal membrane oxygenation. Crit Care 2011, 15:R275.

2. Robson R: The use of bivalirudin in patients with renal impairment. J Invasive Cardiol 2000, 12 Suppl F:33F-36.

3. Dyke CM, Smedira NG, Koster A, Aronson S, McCarthy HL 2nd, Kirshner R, Lincoff AM, Spiess BD: A comparison of bivalirudin to heparin with protamine reversal in patients undergoing cardiac surgery with cardiopulmonary bypass: the EVOLUTION-ON study. J Thorac Cardiovasc Surg 2006, 131:533-539.

4. Koster A, Weng Y, Böttcher W, Gromann T, Kuppe H, Hetzer R: Successful use of bivalirudin as anticoagulant for ECMO in a patient with acute HIT. Ann Thorac Surg 2007, 83:1865-1867.

5. Grimaldi A, Ajello S, Scandroglio M, Melisurgo G, Gardini C, De Bonis M, Bove T, Calabrò MG, Maj G, Zangrillo A, Pappalardo F: Intracardiac clots masked by extracorporeal membrane oxygenation venous cannula. J Cardiothorac Vasc Anesth 2012, 26:e13-14.

doi:10.1186/cc11314

Cite this article as: Ranucci M: Bivalirudin and post-cardiotomy ECMO: a word of caution. Critical Care 2012, 16:427. 